\title{
Information and Meaning in Deterministic Chaos: A Blochian Perspective ${ }^{\dagger}$
}

\author{
Rainer E. Zimmermann ${ }^{1,2, *}$ and Xiaomeng Zhang ${ }^{3}$ \\ 1 Faculty Sudium Generale, University of Applied Sciences, D-80636 Munich, Germany \\ Clare Hall, Cambridge CB3 9AL, UK \\ 3 School of Liberal Arts, Renmin University, Beijing 100872,China; utopia_1990@163.com \\ * Correspondence: rainer.zimmermann@hm.edu \\ + Presented at the IS4SI 2017 Summit DIGITALISATION FOR A SUSTAINABLE SOCIETY, Gothenburg, \\ Sweden, 12-16 June 2017. \\ Published: 9 June 2017
}

Recently, in his 2012 Ph.D. thesis, Craig Hammond has given interesting insight into a possible relationship of Ernst Bloch's philosophy of the utopian shining forth of future projects on the one hand and the modern theory of deterministic chaos and fractal geometry on the other [1]. Concentrating in particular onto the Blochian concept of the Lived Moment, the emergence of information and meaning is discussed within this context. The idea is to find an onto-epistemic basis for the foundation of human reflexion centred on both rational and irrational discourse strategies within the objective as well as subjective frameworks of given world-views.

\section{References}

1. Craig, A. Towards a Neo-Blochian Theory of Complexity, Hope, and Cinematic Utopia; Lancaster University: Lancaster, UK, 2012.

(C) 2017 by the authors. Licensee MDPI, Basel, Switzerland. This article is an open access article distributed under the terms and conditions of the Creative Commons Attribution (CC BY) license (http://creativecommons.org/licenses/by/4.0/). 